\title{
LOCAL GOVERNANCE AND NETWORK-BASED POLICIES FOR HOUSING ENERGY-RELATED RENOVATIONS: INSIGHTS FROM A PORTUGUESE CASE
}

\author{
MARIA ISABEL ABREU, RUI A. F. DE OLIVEIRA \& JORGE LOPES \\ Polytechnic Institute of Bragança, Portugal
}

\begin{abstract}
Local level energy policies are gradually being seen as a main driver to raise energy efficiency in the housing sector which is claimed to have a high potential for energy savings. Local initiatives are already part of energy policies aiming to go beyond the usual top-down government's approach that stems from the interlinkage between national and international policies. Hence, a shift from government to governance is in transition, grounded not only but also in dialog and partnerships involving multiple local actors from different levels in networks rather than in hierarchical organizations. However, little research has been carried out so far regarding the understanding of the specific challenges and the potential of such local governance strategies, as well as their support by national policies. Semistructured in-depth interviews with different stakeholders involved were conducted to make emerge key subjects to this critique. The research outcomes shed some light on the fact that proximity with the homeowners in energy policies is an ultimate key to pursue their success. Municipalities interweaved with other local organizations seem to have promising abilities and structures to be facilitators and intermediaries in order to act as policy vehicles to engage the homeowners in a house renovation practice. The results also suggest that strengthening the sense of neighbourhood, community and cooperation pave the way to empowering network-based programmes. Insights about how local public and private parties together could collaborate in innovative local policies schemes to promote house energy-related renovations are revealed.
\end{abstract}

Keywords: housing energy-related renovation, energy policies, homeowners, local bodies, local networks, information tools.

\section{INTRODUCTION}

The housing sector represents about $74 \%$ of the European building stock ( $82 \%$ in Portugal) and is mostly inhabited by the owners, $70 \%$ on average in the European Union [1]. Despite this sector having a vast energy saving potential [1], the weighted annual house energy renovation rate in the EU27 is still around 1\% [1] and deep renovations are carried out only in $0.2 \%$ of the building stock per year [2]. Hence, it is fundamental to engage homeowners in the renovation of their houses through urgent and tailored energy policies to enable a stepchange in the home renovation market rates. There is a growing recognition that to achieve goals in energy policy, a mix of programmes within a comprehensive strategy that grasps economic, social and environmental areas is crucial [3], [4]. Two types of general policy approaches are prominent today. One involves the top-down policies, from national governmental initiative interconnected with international policies. The other comprises local level initiatives promoted by local bodies in collaboration with other private market parties or even bottom-up citizens' initiatives. To listen to the homeowners' expectations as part of the local policies strategies [5] or embedding policy projects locally are new challenges for energy policy-makers [6]. Local networks-based initiatives as part of a new local governance approach within communities are reported by former studies as one of the most trusted sources of awareness and information by many householders [6]. Thus, the mobilization of cities, local and regional authorities, stakeholders, national governments and citizens will be the key to sustaining energy policies [1]. Hence, the knowledge about the real capacity and 
capability of cities' initiatives to increase housing renovation and the understanding of the differences across citizens' communities to understand their motivations concerning energy policies is paramount [3]. Although many local authorities are already implementing local initiatives amongst homeowners, we still have insufficient knowledge about them and we know little about experience from such policies [3].

The aim of this paper is to make key issues emerge, to bring new insights about the establishment of local networks-based initiatives in order to encourage owners to energy renovate their houses. From the knowledge and perspective of involved Portuguese local stakeholders, the drives, challenges and the potential for local schemes to be implemented is discussed in order to shed light on the conditions and limitations of different possible efforts. To pursue this aim two main research questions were established: how social proximitybased approaches and knowledge networks schemes affects the way homeowners adopt housing renovation practices and what role local bodies and practitioners are willing and prepared to play within a governance and community-based policy environment for promoting housing renovation.

\section{MATERIALS AND METHODS}

A qualitative in-depth exploratory study was used to make new topics emerge about local governance and networks for housing renovation policy. A set of 14 semi-structured interviews were conducted with Portuguese stakeholders involved in the housing renovation market between October 2020 to March 2021, with a length of approximately 60 minutes, via video-conference. Studies suggest that seven interviews are sufficient for making relevant data emerge [7], however the additional interviews conducted provided redundancy and richness of data. This type of interview enabled the respondents to describe their experiences in their own terms and thereby to redefine the scope of the interview questions where pertinent. Although it was guided by the research questions, information might not have emerged from questions based entirely on the interviewers' notions about the subject. The interviewees were selected to engage with the following areas in order to cope with the research questions: case studies of renovations; relevant knowledge and expertise about the Portuguese renovation market, comprising local bodies and citizen network initiatives for housing renovation, and professionals' perspective involved who communicate with homeowners. Three local leaders with some involvement in energy-related schemes, three energy experts with long-time experience, three private market actors (constructors and craftsmen) and five homeowners of single-family houses who have made some kind of energy renovation in their house, were interviewed. Six from the group of leaders, experts and market actors were also renovator homeowners.

The data collected was confronted, analysed and discussed through a quality research method. The interviews were recorded and then their transcripts were coded and categorized using a realist theory approach which detect the most common themes along the transcriptions in line with the research questions but also try to see how the previous knowledge about the subject might be addressed and enlighten by the data [8]. Qualitative findings from small sample interviews followed a statistical theory of small sample qualitative research [7]. 


\section{CONTEXTUAL BACKGROUND}

\subsection{Short brief about how the homeowners decide for renovation}

Firstly, step-by-step housing renovations and not one-time events dominate by far as a continuous improvement for living in and maintaining homes [9]. The renovation decision process, which is a negotiation at the households' level, has been studied in a novel socioeconomical perspective by some authors [10]-[13] (Fig. 1), pointing out that energy-related renovations normally get merged with the non-energy renovations [9], [11], [14].

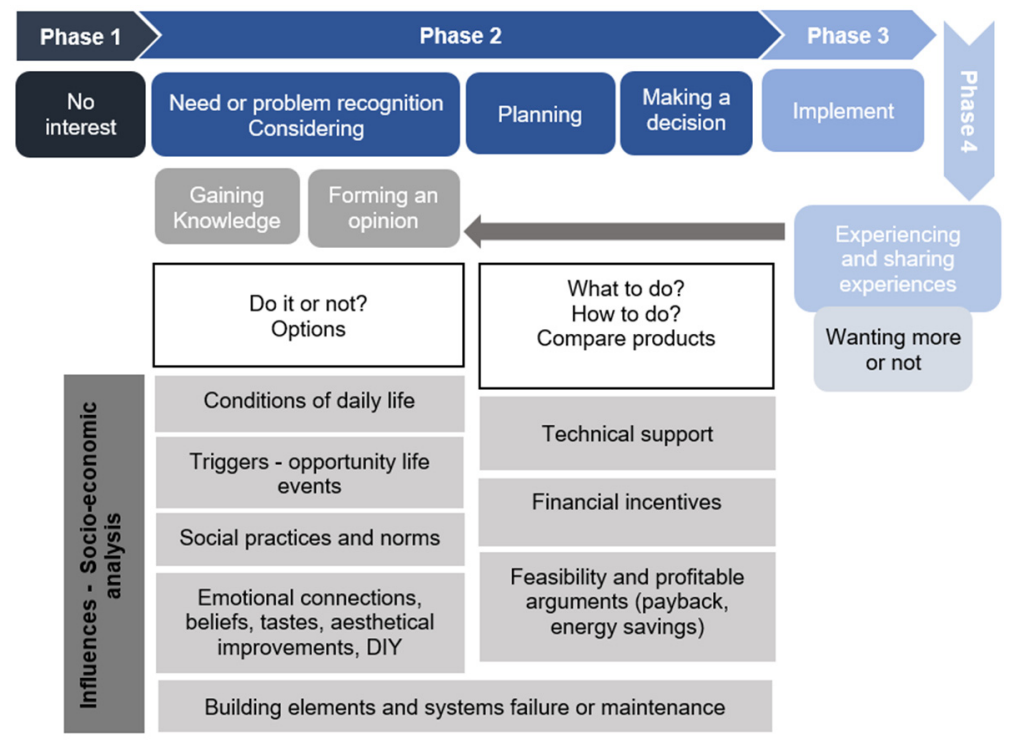

Figure 1: Conceptual scheme about housing renovation decision process in a socioeconomic approach. (Source: Based on [10], [12], [13], [16].)

For a long time, pay-back times, energy savings and rational approaches were considered as main arguments to homeowners for making energy improvements nevertheless the most recent research suggests energy renovation actions cannot be merely understood from an economic viewpoint but also in a practice theory perspective [15] where the underlying influences to begin with a renovation are shaped mostly by householders' everyday practices, life cycles, lifestyles and social values [16]. Through this line of inquire, energy-related renovations are seen as any other daily practice and ruled by four interlinked elements: materials or technologies; know-how and habits; meanings or engagements and institutionalized knowledge and rules sustained by social values [15], [17]. Therefore, it is not only a question of giving homeowners the right information and motivational arguments but to see them as socially contextualized individuals who have common and conventionalized domestic routines, carry embodied knowledge and skills, follow social norms of what is normal to do and to say influenced by knowledge networks where they seek and compare information and share experiences [15]. The "success stories" shared in a network-based level seem promising to motivate homeowners [3] which brings the "experiencing" phase of the renovation process to a relevant status (Fig. 1). Consequently, it 
is important that policy-makers find means to reach what is important for the homeowners [18] focused on the social context of building renovation, preferably early enough in the decision-making process [15], [16].

\subsection{The shift from government to governance and the local network approaches to energy policies}

Traditionally local and national authorities have been setting up policy mix instruments in a top-down-based interference but should devise and facilitate ways of working through local governments and citizens' initiatives [5]. The European Commission claimed recently that intends to reinforce the technical assistance and aim to work in close partnership with local and municipal authorities [1]. Recent evidence demand for governance at local level, where governments interact with citizens and communities on a daily basis [19]. Governance is a process where it is the decision-making amongst the actors involved in a collective problem that drives to the creation, underpinning or reproduction of social norms and institutions [20]. It allows a comprehensive inclusion of non-state stakeholders from different levels in networks and approaches with newer voluntary instruments [21]. In reality, social interaction and norms together with knowledge networks around the homeowners already play an essential role in creating and sustain know-how for householders' mundane practices of everyday life which can be intercepted with the understanding of what assemble energy renovation actions [15]. For exchange of advice and practical help purposes, usually these networks are structured through informal conversations within socializing practices between people or through humble consultation of constructors and craftsmen from the social sphere around the homeowners. Thus, mobilising social or expert knowledge networks, identifying relevant participants, establishing legitimacy amongst the involved actors and resolving conflicts are challenges within a local network-based governance [3]. Studies reveal that proximity schemes grounding their efforts on a combination of both socially and economically approaches at local level have led to substantial results in housing renovation [22], [23]. Firstly, municipalities or even regional authorities can be facilitators for local collaboration between different interested parties, providers of frameworks for integrated solutions on financing, technical advice and solutions support [24]. Together with utility companies they have an important role in creating the necessary regulatory agenda, market conditions and skills [9] (Fig. 2). Secondly, local authorities, through a service of energy consultancy' desks, can be mobilizers of "a culture of energy" spread in the community [15] and address directly the homeowners to lift their interest in a house renovation journey or offer proper conditions to help citizens' voluntary search for information in the "considering" phase of the decision process (Figs 2 and 3). A direct interaction with each household is possible but remains fragile, partly due to the high costs of contacting individually [3]. Single-family houses are a challenge to policy-makers because of the many units, many owners and lack of shared organisation connecting the homeowners [3]. This bias might be accomplished focusing on a more collective area-based approach (neighbourhoods, villages, etc.) [3] (Fig. 3). Despite the difficulties of engaging the public in community initiatives, a framework of interventions can be used to enable individuals to participate in communal projects [25]. Involving civil society in the drafting of local plans and strategies as for example making pre-draft consultations is an example [26]. Public meetings, where building professionals are invited, to promote and present their materials and skills to the homeowners who in turn put their doubts and responding with their own experience on renovation it is a worthy network initiative registered [5] (Fig. 3). Hereafter, in the decision "planning" phase, 


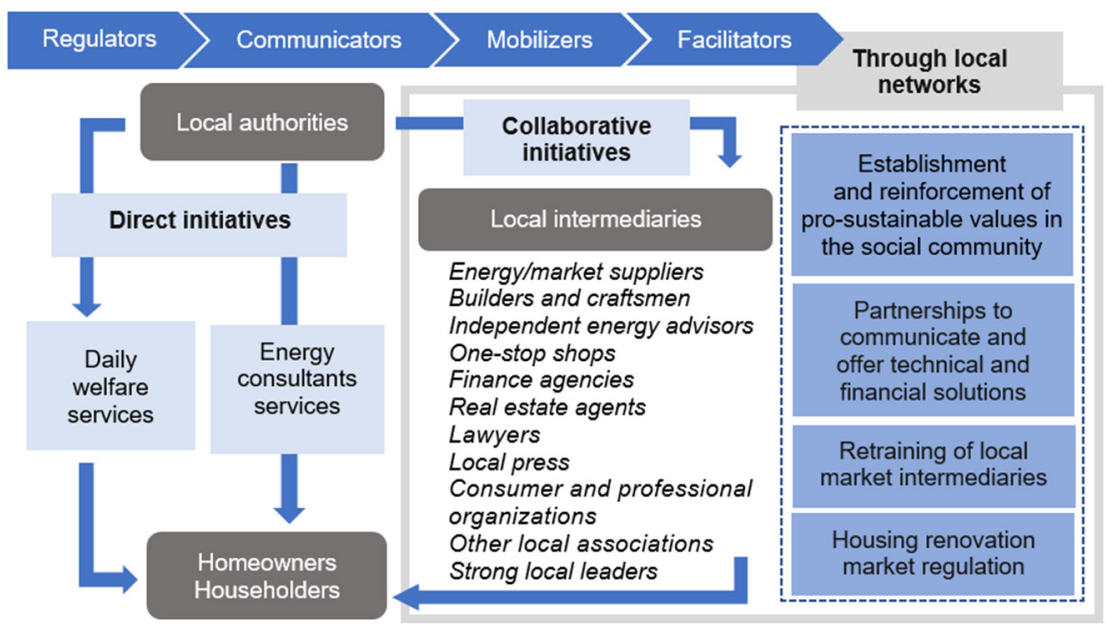

Figure 2: Local authorities' roles and initiatives models to address homeowners to renovate through a network-based governance. (Source: Based on [3], [29].)

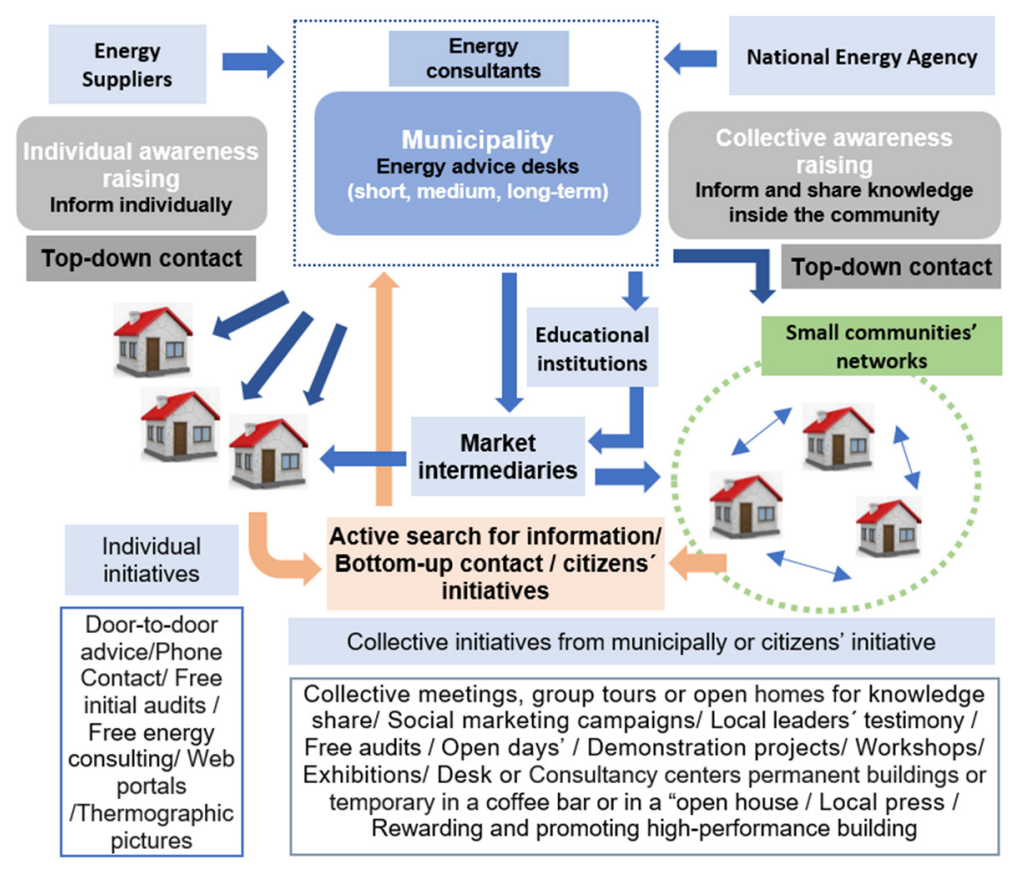

Figure 3: Network-based scheme approaches for addressing housing energy renovations. (Source: Based on [3], [29].)

a more professional and practical support is needed to engage homeowners [27] because interested citizens in renovation often abandon the renovation idea before putting it into practice [28]. The experiences indicate that local consultancy services (easily accessible, 
impartial and subsidized) with different levels of involvement (duration, location and resources) can play a major role [3], [27]-[29]. Here expert intermediaries walk very closely with the client and develop tailored advice, in a neighbourhood context or not, within local communities [29]. One-stop shop is another possible model that translates the disjointed supply side into one all-inclusive renovation solution helping the client to select financial schemes [28]. Ultimately, local climate governance is emerging [30] which includes different means of urban energy intermediation [31].

\section{RESULTS AND DISCUSSION}

4.1 How social proximity-based approaches and networks-based knowledge affects the way homeowners adopt housing renovation practices

Proximity schemes between authorities, renovation market actors and homeowners was unanimously recognized by all respondents as favouring communication and engendering trust helping to overcame operational obstacles. The general idea of many of the energy experts is that an atmosphere of face-to-face and closer interpersonal proximity with citizens in a proper environment can enable a more effective explanation of both arguments and solutions making possible to have a more accurate evaluation of the community. Both leaders and energy experts interviewed referred good experiences in working with small communities, even in large cities contexts.

Two types of local knowledge networks around the Portuguese householders became salient in the outcomes. A social network, informally established, and an organized and skilled network. The findings indicate that the first have more influence in the initial phases of renovation decision process and the second gets more relevance the closer the "what to do and how to do" phase is. The majority of homeowners revealed that they always searched for information and advice somewhere before and after they take the decision to renovate. In general, all recognized they felt the lack of knowledge and they needed to overcame a cognitive burden when pursue information because it was not easily accessible. More often than not, some continued to implement home improvement measures by receiving baseline levels of advice, however more than a half recognized that they had bad experiences. Relatives, friends and neighbours' opinions, attitudes and experiences influenced somehow the decision, from the "considering" to the "implementation" phase, mainly in the choice of renovation solutions, products and professionals. Homeowners also revealed that they were more willing to adopt changes when the reactions of their peers were positive. One of the homeowners stated: "In fact, we started to think about renovating mainly because we were going to have a baby at the time and our home was inherited but after that we realized that we do not knew so much about the process, then we started to ask family and colleagues for opinions." The majority pointed out that the search for information was made simply through informal conversations or just made more aware daily about the subject. Virtual social networks, where the respondents joined thematic groups, was one valuable source of information and support used to strengthen the idea of going forward with the renovations. A couple of homeowners admitted that they had already a "dream list" of some general renovations they wish to put into practice but one drive to make house improvements was their neighbours having started gradually to make small home renovations, part of them energy improvements. "We witnessed that some few started by doing some small improvements that induced them to the following renovations", they said. Strong community social relations lead to better dynamics in communication. 
Contractors and craftsmen also constituted one of the most reliable and low-cost source of information through a more skilled knowledge network. An informant assumed "The few craftsmen we knew build with us a personal trust-based relationship over a lengthy time of periods and they supported us through the little few renovations we did". But the lack of knowledge in comprehensive renovations they still demonstrate was several times mentioned in the conversations. This kind of apparently more skilled network offers many times a contradictory know-how and advice because is fragmented between different types of craftsmen and they are mainly concerned with business, to fit the economy of homeowners (but not with profitability) and to build a good reputation for future works.

More than one homeowner who did consult an energy advisor referred that sometimes some of the information they transmitted did not fit entirely into their wishes and needs at the moment and some homeowners also assumed that they were tempted to compare information between the energy advisors' recommendations and what they already know from their social network. One energy expert detailed from his experience that many times the owner-occupier had already made some decisions when he entered the scene, homeowners only seek validation for their former decisions, not being very responsive to rational arguments. He underlined that strong persuasive skills were needed to change homeowners' ideas embedded in what he called "emotional choices". Another respondent points to the oral information that he received from an energy advisor diminished the many fears and doubts he had. "The possibility of contacting freely and easily the advisor to clarify some aspects gave me confidence to go forward in many stages of the process". They considered in general energy advisors as reliable professionals.

Another issue salient in the narratives analysis was that a large spectrum of social influences make rise or reinforce in householders' minds the idea of starting energy improvements at home. From the homeowners' individual beliefs, domestic life circumstances, personal events or life cycles to the social network's norms around. The aspirations for a nice and better house appearance together with displaying the social identity or the lifestyle established by the community's social norms about what a house should look like was mentioned in three interviews. The outcomes suggested that norms that sustained a social network gradually persuade, in a daily basis, homeowners' personal values about what kind of house they wish to have and to be visible to others. Maybe this justify in part that visible renovations, independently of knowing they were economically wise decisions or not, tend to be the most adopted. To understand the social norms and values of each community is central and this is only possible with policy-makers working in a proximity-based approach through local partnerships where real estate agents, local associations and local market partners can know well the circumstances of a specific community.

The findings revealed also different homeowners' interests about renovation which suggest that different knowledge networks schemes could be established by local polices to target different types of homeowners' profiles. For example, a homeowner interviewed assumed a motivating aspect, she valued house design magazines to dream with her ideal home where she found some home design style ideas mixed with energy-related solutions. Personal taste mixed with house appearance was a concern to renovate that emerge for more than half of the recorded stories. Networks based in collaboration between public bodies and design magazines or home industries, to harness house design, lifestyle, social status and consumer choice, could be interesting policies instruments. Two of the homeowners also revealed they were quite interested to be involved in the process of renovation. They stated they felt lack of DIY networks for information share or to see in loco ongoing renovations. This suggest that local authorities could sponsor the training of frontline staffs from DIY and bricolage retailers and shops to support DIY homeowners and open space to group tours and 
open homes to see examples of renovations. Some homeowners were also fascinated by technology and innovative products for homes which was an aspect raised by the energy experts to make Portuguese homeowners take energy improvement actions. They revealed that several times this was more often influenced by the social network than by a skilled network of professionals. Interviews narratives exposed that sustainability can be associated more with the adoption of new "green" technologies than changes in daily habitus to reduce energy consumption. To have the latest solar system or heat pump is seen as something some people wish for a question of prestige. Local authorities' partnerships with local associations and with private supply market actors could mobilize knowledge networks for innovative technologies adopters.

Hence, local authorities' collective approaches to promote housing renovation awareness and practices need to target not only geographical areas and but also groups of homeowners via social virtual networks, who can be from different locations, but with common understandings. This communicative channels generate today strong motions and dynamics that make arise collective bottom-up initiatives and social movements. Nevertheless, a bias frequently recognized in the interviews is the lower interest and involvement of citizens in participating in community goals in general. Curiously, one of the local leaders (simultaneously a renovator) considered that proper urban planning and public facilities which enables citizens to casually meet and being together frequently in public outdoor spaces (green parks, expositions and meetings, solidarity projects, etc) reinforce the social relations and sense of neighbourhood. He expressed he experienced this sense with himself. Other local leaders commented: "To reach the homeowners is not only contact them it is also to enable the most proper facilities to make homeowners fell impelled to voluntary search for information or organize initiatives inside a community-based environment". The results also suggest that initiatives from local authorities which develop the sense of community and a culture of active citizen participations that apparently seems to have nothing to do with housing energy renovation can indirectly motivate this market. Mobilizing knowledge networks that put the energy efficiency in houses as a common topic of conversation and as fashionable as, for example, home design seems an interesting pathway.

From the analysis of data was also clear that different social and economic situations strongly influence possibilities for renovating houses. Establishing differentiated locally network-based initiatives adapted to different local communities' specificities is important.

4.2 The role local bodies and practitioners are willing and prepared to play in a governance and community-based policy perspective.

With regard to local authorities being the link to communicate energy efficiency and support housing energy renovations, the overviews in the interviews were diverse. The majority of local leaders and energy experts consider local authorities better than national ones at responding to homeowners' needs. However, from the homeowners' perspective, almost all reported many doubts about municipalities' communicative skills and support effectiveness. For the householders, there is a distrust of public services in general. But the interviewees recognized that they have privileged facilities to ensure the establishment of local initiatives and collaborations. One of the leaders interviewed specified: "Remember that municipalities are responsible for the overall planning and administration of the city or village, comprising provision of welfare services, planning and sustainable development. They have proximate physical structures well set up to support citizens, involving face-to-face services where individuals can go to put their problems on a daily-basis". Portuguese municipalities have invested in a closer proximity with citizens through one-stop multiservice desks, which 
provide and facilitate several services in one single space. One of the energy experts suggested that moments when householders need to contact municipalities to solve personal circumstances or require several licences or permits (even for a non-energy renovation) could be opportunity times to raise awareness about sustainable practices. Combination of useful services with energy efficiency needs creative policy approaches. An energy expert said: "The requirement of some basic and wellbeing services allow municipalities to know some details, for example, a new stage in the homeowners' life or a new house". During the interviews with the homeowners, house renovation events were often related with life stories, suggesting that the beginning and end of homeowners' life cycles or life events can lead to more willingness and need to change the house. Municipalities or other local bodies can also have some privileged information about some of these moments to communicate in a targetbased approach. In fact, this can be privileged means to approach a certain category of homeowners in a proper time-stage. This was reinforced by energy experts who experienced several times to arrive too late with regard to the origin of willingness of people to engage in renovations.

When private market actors were asked for their involvement in the process of housing renovation, they generally stated that they are rarely invited to participate in policies initiatives with the local authorities' sponsorship. In general, they still do not recognize themselves as building energy efficient practitioners. Some informants consider that they should be trained to improve their skills in a whole building renovation perspective which is reasonable since the majority of the home energy renovations are made continually and simultaneously with non-energy renovations [9]. They claim that there are few training programmes beyond the ones for architects and engineers. One craftsman said: "National Energy Agency could support training programmes for us at local level creating partnerships with professional associations". One of the energy experts revealed: "Many times when we are asked to give support to homeowners, they had already made some previous works recommended by a constructor or craftsman and the solution was not the most cost-effective". Some experts also pointed that real estate agents and supply side parties are important to collaborate with local policy-makers because of their market know-how and experienced skills in communication, persuasion and marketing.

Recently the Portuguese long-term strategy for building renovation gives for the first time a great significance to energy consultancy desks which local authorities must operationalize [2]. One of the experts interviewed considered energy advisors' recruitment by municipalities a legal step to overcome and called the attention to the fact that the Portuguese energy advisors are well prepared to offer technical advice but they lack training in communication skills or to provide end-users with wider arguments for renovation. From the group of homeowners interviewed who ask for support of energy advisors during their renovations, almost all considered that this support is more cost-effective than a simple simulation software tool available online. "It is easier to trust experts as persons than in systems" stated one of the homeowners.

\section{CONCLUSIONS}

Under the research questions formulated, this exploratory study revealed key topics that can play a significant role in shaping local network-related strategies to boost and sustain housing renovation practices. The outcomes strengthen the view that proximity is one ultimate factor to influence homeowners. This proximity is revealed through local-level knowledge networks some of them well established communication channels to share information. The findings suggested also that energy-related renovations are already a matter of conversation and trust but this can be further developed through target-based local knowledge networks. 
Social networks or skilled knowledge networks were identified. Primarily, networks of family, friends and colleagues are always important since the beginning of the homeowners' decision journey to help to increase the interest of not yet committed energy users. To share experiences and to have positive feedback of peers was shown to affect somehow homeowners' behaviour in renovations. The strong influence of social values and norms in the community to activate potential renovators was also salient in the study outcomes. This suggest that there are implicit knowledge networks inside a community that persuade homeowners to renovate just because they want to display a certain social identity in the community in line with what is socially established about what an ideal house should be. If policy-makers and local authorities could define strategies to put house energy renovations as a cultural marker of social status and fashion in a community, this could help to induce homeowners to renovate beyond the direct awareness raising and communication actions.

Additionally, diverse homeowners' approaches or perspectives for renovation lead to the acknowledgment that there are different homeowners' interests and categories and suggest that tailored and assorted knowledge networks could be mobilized and induced by local authorities in partnership with selected local actors. Collective energy policy approaches by local bodies should create synergies to mobilize and establish diverse community knowledge networks, not only based in geographical definitions (villages or neighbourhoods) but in areas of interest through social virtual networks. Groups of homeowners could be associated by common values and understandings, as for example networks constituted by DIY, technologies or aesthetics and home fashion adopters.

The several actors interviewed reinforced the important role of municipalities as facilitators, mobilizers and communicators. These bodies can situate the housing renovation programmes in other framings of urban development combining it with other municipal goals. A community-oriented urban planning, creating public spaces for recreation and leisure and public events for citizens to meet and be involved together to pursue collective goals, are promising examples. Local authorities are also privileged bodies to promote energy renovation because at the same time they offer welfare services where they can communicate energy efficiency to citizens. Furthermore, they also can reach privileged information about citizens' life cycle and personal events to plan appropriate time-stage approaches. Local professional associations and organizations could play a crucial role as partners of municipalities to understand and mobilize the homeowners and train professionals. The findings revealed also that Portuguese private market actors are willing to be further involved and work together in the design of local schemes and initiatives. Craftsmen and constructors in Portugal are already an important part of the social network but they do not feel important in the process and need more training to give a comprehensive support and not fragmented advice. Energy advice and support services can constitute a strong knowledge basis to simplify the renovation decision process through support and practical help in order to increase demand in energy renovations. Energy advisors are recognized as reliable for the homeowners along the process of decision-making because face-to-face and closer interpersonal proximity is an important factor valued by the homeowners. Real estate agents and supply renovation market actors are underutilized. They are well-suited to take in hand particular situations through a public relation work and as experts in communicative skills and marketing know-how.

The promotion of strategies to increase energy efficiency on the local communities and the establishment of collective processes can be currently part of local authorities' governance agenda. Policies being locally embedded can promote a positive community culture by encouraging projects benefiting the entire neighbourhood or specific groups, helping current house occupants to improve their living conditions and overcome negative 
emotions about housing renovation. New local and regional forms of collaboration and information platforms are needed and the definition of national and local policies must be carried out by closely communicating with local stakeholders.

Possible future developments of this study could be to understand and define more specifically the role of each local body in the housing renovation process to define an operational network program of collaborations and partnerships adapted to different social and economic local situations.

\section{REFERENCES}

[1] European Commission, The Renovation Wave: The European Green Deal, https://ec.europa.eu/energy/topics/energy-efficiency/energy-efficient-

buildings/renovation-wave_en\#a-renovation-wave-for-europe. Accessed on: 6 Apr. 2021.

[2] Portuguese Government, Long term strategy for the renovation of buildings in Portugal (ELPRE), Presidency of the Council of Ministers 8-A/2021, 2021. https://dre.pt/web/ guest/home//dre/156295372/details/maximized?print_preview=print-preview.

Accessed on: 8 Apr. 2021.

[3] Gram-Hanssen K., Ole Jensen J. \& Friis F., Local strategies to promote energy retrofitting of single-family houses. Energy Efficiency, 11, pp. 1955-1970, 2018.

[4] Nilsson, M., Zamparutti, T., Petersen, J.E., Nykvist, B., Rudberg, P. \& McGuinn, J., Understanding policy coherence: Analytical framework and examples of sectorenvironment policy interactions in the EU. Environmental Policy and Governance, 22, pp. 395-423, 2012. https://doi.org/10.1002/eet.1589.

[5] Galvin R. \& Sunikka-Blank, M., The UK homeowner-retrofitter as an innovator in a socio-technical system. Energy Policy, 74, pp. 655-662, 2014.

[6] Beillan, V., Huber, A., Battaglini, A., Goater, R., Mayer, I. \& Trotignon, R., Barriers and drivers to energy-efficient renovation in the residential sector: Empirical findings from five European countries. ECEEE 2011 Summer Study: Energy Efficiency First: The Foundations of a Low-Carbon Society, 2011.

[7] Galvin, R., How many interviews are enough? Do qualitative interviews in building energy consumption research produce reliable knowledge? Journal of Building Engineering, 1, pp. 2-12, 2015.

[8] Crouch, M. \& McKenzie, H., The logic of small samples in interview-based qualitative research. Social Science Information. 45, pp. 483-499, 2006.

[9] European Commission, Comprehensive study of building energy renovation activities and the uptake of nearly zero-energy buildings in the EU, Final Report, 2019. https://ec.europa.eu/energy/studies/comprehensive-study-building-energyrenovation-activities-and-uptake-nearly-zero-energy_en. Accessed on: 6 May 2021.

[10] Klöckner, C.A. \& Nayum, A., Specific barriers and drivers in different stages of decision-making about energy efficiency upgrades in private homes. Frontiers of Psychology, 7, p. 1362, 2016. https://www.ncbi.nlm.nih.gov/pubmed/27660618.

[11] Baginski, J.P. \& Weber, C., A consumer decision-making process? Unfolding energy efficiency decisions of German owner-occupiers. HEMF Working Paper, No. 08/2017, 2017.

[12] Broers, W., Vasseur, V., Kemp, R., Abujidi, N. \& Vroon, Z., Decided or divided? An empirical analysis of the decision-making process of Dutch homeowners for energy renovation measures. Energy Research and Social Science, 58, 101284, 2019. https://doi.org/10.1016/j.erss.2019.101284. 
[13] Ebrahimigharehbaghi, S., Qian, Q.K., Frits, M. \& Visscher, H.J., Unravelling Dutch homeowners' behaviour towards energy efficiency renovations: What drives and hinders their decision-making? Energy Policy, 129, pp. 546-561, 2019. https://doi.org/10.1016/j.enpol.2019.02.046.

[14] Sunikka-Blank, M., Galvin R. \& Behar C., Harnessing social class, taste and gender for more effective policies. Building Research and Information, 46(1), pp. 114-126, 2018. https://doi.org/10.1080/09613218.2017.1356129.

[15] Bartiaux, F., Gram-Hanssen, K., Fonseca, P., Ozolina L. \& Christensen, T.H., A practice-theory approach to homeowner's energy retrofits in four European areas. Building Research and Information, 42(4), pp. 525-538, 2014.

[16] Wilson, C., Crane, L. \& Chryssochoidis, G., Why do homeowners renovate energy efficiently? Contrasting perspectives and implications for policy. Energy Research and Social Science, 7, pp. 12-22, 2015. https://doi.org/10.1016/j.erss.2015.03.002.

[17] Judson, E.P. \& Maller, C., Housing renovations and energy efficiency: Insights from homeowners' practices. Building Research and Information, 42(4), pp. 501-511, 2014. https://doi.org/10.1080/09613218.2014.894808.

[18] Galvin, R., Why German homeowners are reluctant to retrofit. Building Research and Information, Research Paper No. 42, pp. 398-408, 2014. http://dx.doi.org/10.1080/09613218.2014.882738.

[19] World Organization of United Cities and Local Governments. https://www.uclg.org/ en/action/decentralisation-governance, Accessed on: 1 Apr. 2021.

[20] Hufty, M., Investigating policy processes: The governance analytical framework (GAF). Research for Sustainable Development: Foundations, Experiences and Perspectives, eds U. Wiesmann \& H. Hurni, Geographica Bernensia: Bern, pp. 403424, 2011.

[21] Van der Heijden, J., The new governance for low-carbon buildings: mapping, exploring, interrogating. Building Research and Information, 44, pp. 575-584, 2016. https://doi.org/10.1080/09613218.2016.1159394.

[22] Gillich, A., Sunikka-Blank, M. \& Ford, A., Designing an "optimal” domestic retrofit programme. Building Research and Information, 46(7), pp. 767-778, 2017. https://doi.org/10.1080/09613218.2017.1368235 j.envsci.2016.06.021.

[23] Webber, P., Gouldson, A. \& Kerr, N., The impacts of household retrofit and domestic energy efficiency schemes: A large scale, ex post evaluation. Energy Policy, 84, pp. 35-43, 2015. https://doi.org/10.1016/j.enpol.2015.04.020.

[24] Kern, K. \& Alber, G., Governing climate change in cities: modes of urban climate governance in multilevel systems. Competitive Cities and Climate Change, OECD Conference Proceedings, pp. 171-196, 2009.

[25] Axon, S., The good life: Engaging the public with community-based carbon reduction strategies. Environmental Science Policy, 66, pp. 82-92, 2016.

[26] Rivas, S. et al., The Covenant of Mayors: In-Depth Analysis of Sustainable Energy Actions Plans, EUR 27526 EN, JRC95656, Publications Office of the European Union, 2015.

[27] Mahapatra, K. et al., Business models for full service energy renovation of singlefamily houses in Nordic Countries. Applied Energy,112, pp. 1558-1565, 2013.

[28] Boza-Kiss, B., Bertoldi, P., Della Valle, N. \& Economidou, M., One-stop shops for residential building energy renovation in the EU. Report number: JRC125380, European Commission, 2021. 
[29] Meijer, F., Straub, A. \& Mlecnik, E., Consultancy centres and pop-ups as local authority policy instruments to stimulate adoption of energy efficiency by homeowners. Sustainability, 10, p. 2734, 2018.

[30] European Bank for Reconstruction and Development (ERBD), Energy Efficiency Governance: Handbook, 2nd ed., International Energy Agency (IEA): Paris, 2010.

[31] Hodson, M., Marvin, S. \& Bulkeley, H., The intermediary organisation of low carbon cities: A comparative analysis of transitions in Greater London and Greater Manchester. Urban Studies, 50, pp. 1403-1422, 2013.

https://doi.org/10.1177/0042098013480967. 